\title{
EL ACRÓBATA EN LOS TIEMPOS DEL NEOLIBERALISMO
}

\section{Un comentario sobre Peter Sloterdijk}

\author{
Sandro Luce
}

Università degli Studi di Salerno

\section{THE ACROBAT IN NEOLIBERAL TIMES}

\section{A commentary on Peter Sloterdijk}

\section{Premisa}

Intentar preguntarse alrededor de la actual condición humana significa emprender una operación compleja, que esconde numerosas insidias. Ya Hannah Arendt nos advertía del peligro por el cual tal cuestión se podía convertir en una investigación sobre la naturaleza humana, ${ }^{1}$ corriendo el riesgo de buscar respuestas en divinidades metafísicas o —en una sociedad secularizada como la nuestra — en las 'nuevas divinidades empíricas', las ciencias. El compromiso de comprender las formas de actuación y las maneras con las que el hombre se descubre a él mismo y al mundo se basa cada vez con más frecuencia en los conocimientos ofrecidos por la corriente biologista-evolucionista y por los estudios sobre las estructuras cognitivas o — según otras perspectivaspor los más recientes progresos de la ingeniería genética. Ellas se ocupan de detectar lo qué significa la vida humana y cómo funciona, con la inevitable consecuencia de vaciar el estatuto ontológico del sujeto de cualquier contenido histórico y filosófico, disciplinas reducidas a pleonásticos gorgoteos humanísticos. Sin embargo, se trata de verdades

1. H. Arendt, The Human Condition, The University of Chicago Press, Chicago, 1998. 
que expresan de manera irreflexiva lo que existe: ellas afirman lo que el hombre es, sin preguntarse que es y cómo ha llegado a ser lo qué es, diferentemente de lo que podríamos llamar el tema de 'darse una forma' o de 'hacerse sujeto'. Se trata, pues, de una perspectiva totalmente opuesta a la ofrecida por quien, como Foucault, ha explicado que el sujeto se constituye precisamente a partir de los discursos que lo analizan, lo clasifican y lo objetivizan. Foucault considera la naturaleza humana como un indicador epistemológico, porque desarrolla una función de delimitación y atribución de sentido, que es intrínsecamente variable porque está condicionada por el contexto en que se construye. No tiene sentido hablar de naturaleza humana sin situar dentro de un contexto histórico su significado tras los descubrimientos científicos que caracterizan a aquel específico umbral epistemológico y, sobre todo, teniendo en cuenta que cada umbral no es sino un punto de transición - a través de una ruptura- hacia nuevos ámbitos de conocimiento, por tanto hacia nuevas verdades. ${ }^{2}$ De esta manera, el sujeto es destituido de su potencia fundadora de la realidad, tal como lo concibe la tradición moderna a partir de Descartes, para ser reconducido a su ser deveniente en un proceso constantemente en vilo entre una objetivización pasiva y una subjetivización activa.

Bajo algunos puntos de vista, Du musst dein Leben ändern. Über Anthropotechnick de Sloterdijk se puede interpretar como una refinada descripción del empacho en el que incurre la actual condición humana, tal como la contextual tentativa de reconstituir el sujeto, descrito como vaciado y homogeneizado a lo largo de la modernidad, a partir de la valorización de su actividad práctica, que consta de ejercicios dirigidos a su mejoramiento. El ejercicio, considerado como un comportamiento dirigido a plasmarse y perfeccionarse, constituye la condición de posibilidad de una subjetivización que produce una distinción ética entre aquellos que destacan por no hallarse en lo ordinario, y aquellos que quedan adormecidos en su habitus, inertes y pasivos. Tal como ya afirmaba Nietzsche, el ejercicio es una gimnasia de la voluntad ${ }^{3}$, el hombre realiza su tarea solo cuando es capaz de esquivar el automatismo y las costumbres, por eso una 'buena ascesis' no aspira a la negación sino a la consolidación de la vida, ya que considera la vida misma una prueba de fuerza. Entonces, se trata de unas ganas de vivir que se enlazan con unas ganas de poder, es decir, una vida que se pone a prueba solo si es capaz de ejercer un control sobre ella misma. Pues bien, ¿pero por qué

2. N. Chomsky, N. Foucault, Human Nature: Justice vs. Power. The Chomsky-Foucault Debate, Souvenir Press LTD, London, 2011. Por lo que al concepto de umbral epistemológico se refiere, cfr. M. Foucault, L’Archéologie du savoir, Gallimard, París, 1969.

3. F. Nietzsche, Nachgelassene Fragmente Herbst 1887 bis März 1888; Abd. VIII, Bd. II, de Gruyter, Berlín, 1970, Fr. 9[93], p. 51. 
nuestra posibilidad de salida de un status quo ordinario y pasivizante debe cruzarse necesariamente con un nuevo imperativo categórico — 'debes cambiar de vida' - que produce una especie de auto-trascendencia? ¿Este es un camino posible -entre los que hay- para realizar el deseo de libertad o es un proceso necesario y único en nuestro devenir?

\section{Antropotécnica y técnicas del yo}

Las técnicas de disciplina del yo tienen una larguísima tradición ${ }^{4}$ pero adquirieron un particular significado cuando, a lo largo del siglo XX, la llamada antropología filosófica sacó a luz la interacción entre los procesos de culturización y las prerrogativas biológicas del hombre. En particular, el estudio de Gehlen ha demostrado que la especificidad de lo humano se halla en el hecho de ser una forma viviente cruzada por dos incontinencias: un exceso pulsional (Antriebsüberschuss) y un flujo de estímulos que manifiestan la escasez de un bagaje orgánico y la consiguiente imagen del hombre como ser carente de algo (Mängelwesen). Este dato 'natural' exhibe las condiciones para una tecnicización de lo real, de la cual el hombre necesita para crear las condiciones que puedan ser favorables para su existencia en un mundo abierto e imprevisible. ${ }^{5}$ De ahí que la posibilidad de inmunizarse de los peligros y de la contingencia del ambiente externo produzca un doble y contextual movimiento del viviente quien, por una parte, planea, manipula y plasma el mundo (lo que está fuera) y, por otra parte, limita, inhibe y reglamenta sus propios impulsos (lo que está dentro). La actuación humana pierde cualquier connotación relacionada con los instintos cuando está dirigida a la producción de ámbitos de compensación de las disposiciones naturales: bajo este punto de vista, por medio de procesos de exención, el hombre experimenta el mundo, lo reduce y condensa en símbolos. La dimensión naturalístico-biológica remite a aquella cultural-simbólica en el interior de un espacio circular en el que se halla una continua reformulación entre ambiente y organismo viviente, que lleva a una ininterrumpida evolución de ambos. ${ }^{6}$

Las meditaciones de Sloterdijk se deben considerar a la luz de estas coordenadas filosóficas. La conciencia de la imposibilidad de agarrar la esencia de lo humano se

\footnotetext{
4. Sobre ellas se ha centrado gran parte del estudio de los años ochenta de Michel Foucault, tanto durante las clases dictadas en el Collège de France, como en las dos obras publicadas en 1984, L'usage des plaisir y Le Souci de soi, ambas publicadas por Gallimard, París.

5. A. Gehlen, Der Mensch. Seine Natur und seine Stellung in der Welt, Aula-Verlag, Wiesbaden, 1986.

6. Una premisa epistemológica hacia este enfoque, sobre todo por lo que a la relación entre organismos vivientes y espacios ambientales se refiere, en el ámbito biológico la proporciona K. von Uexküll, Streifzüge durch Umwelten von Tieren und Menschen: ein Bilderbuch unsichtbarer Welten, Rowohlt, Reinbek, 1962.
} 
convierte en la tentativa de aferrar la totalidad de las condiciones, determinando una reflexión teórica que va de la natura hominis a la conditio humana. De hecho, la antropotécnica indica el ejercicio individual y colectivo dirigido a la creación de estructuras simbólico-metafísicas necesarias para hacer frente a la humana vulnerabilidad a través de medidas de prevención reales e imaginarias. Según esta perspectiva, en un principio, el hombre es Homo immunologicus porque confiere una apariencia simbólica a su propia vida, construyendo de manera incesante un puente entre naturaleza y cultura que le permite sobrevivir. Sin embargo, siendo una técnica del yo que plasma al sujeto, el ejercicio también es lo que le permitiría no solo sobrevivir sino también autotrascenderse, alejándose de la mediocridad y pasividad de lo ordinario. Convirtiéndose en sujeto, el hombre se aparta del itinerario biológico-evolutivo a través de un ejercicio de auto-manipulación que lo lleva a la provisoria condición de estar colgado entre lo alto y lo bajo, entre una posibilidad de escalada ascética y un hundimiento en la rutina. Gracias a la antropotécnica, el ser humano vive constantemente bajo el yugo de la autoproducción de sí mismo, del mantenimiento o del mejoramiento de sus propias prestaciones, sometido a una tensión antes ontológica que simbólica, lo cual hace que, por definición, el hombre siempre carezca de algo y que siempre le falte algo por aprender, lograr y conquistar. La condición del hombre es la de un ser acrobático no solo desde un punto de vista biológico - puesto que ya la pura supervivencia es una ardua acrobacia-, sino precisamente porque experimenta una continua tensión sugerida por los condicionamientos simbólicos externos que determinan un conflicto interior. Solo si este va a producir acciones que desquician la banalidad de la costumbre, renovando constantemente la que, de otra manera, solo sería una estéril repetición de ejercicios, la condición del hombre mejora hasta poder alcanzar lo sublime.

\section{Ascesis y fitness: ¿nuevos monasterios?}

El imperativo rilkiano — 'debes cambiar de vida' — nos lleva, pues, afuera de la corriente de la vida ordinaria, es decir, hacia una ascensión llevada a cabo gracias a un conjunto de técnicas que permiten plasmar su propio yo. Empleando una terminología foucaultiana, se esboza la posibilidad de una subjetivización activa que, desde un punto de vista ético, ofrece nuevas ocasiones para interrogarse alrededor de la factibilidad de una vida caracterizada por una constante autosuperación y que, al mismo tiempo, deja numerosas perplejidades desde un punto de vista político. 
A partir de la década de los años ochenta, el gran viraje neoliberal asentó las condiciones teóricas y prácticas para declarar la guerra a la lógica pastoral del modelo welfarista. ${ }^{7}$ La afirmación de un imaginario colectivo cada vez más colonizado por una lógica de tipo estratégico y optimizante basada en las posibilidades/capacidades de construirse como empresario de uno mismo, ha producido evidentes secuelas en términos de disminución de los derechos y de las garantías que — sobre todo en ámbito laboral— habían acompañado la ascensión del estado welferista. Este deterioro del modelo salarial se ha cruzado y ha sido respaldado por la continua - - , bajo muchos aspectos, retórica- incitación a la libertad, a ser lo que uno es, a la responsabilidad de sus propias elecciones, cada vez menos sociales y cada vez más personales, que ha producido un agotamiento de la unión social, construyendo la imagen de individuos libres, autónomos y racionales pero, al mismo tiempo, cada vez más solos y, por esa razón, también más fácilmente manipulables y plasmables. El mismo fitness sigue el ritmo de la lógica del buen funcionamiento y de la optimización económica, una lógica pues que está en sintonía con lo útil, con lo eficiente, con el criterio de la vida, si ésta no está sometida a un criterio de pura supervivencia, sino de potenciación. ${ }^{8}$ De manera inexorable, la autopoyética del yo es heterodirigida por un razonamiento que se afirma como verdadero, el económico-neoliberista, que aleja la vida de una condición de estatismo, para luego volverla a definir como lo que se puede construir y potenciar dependiendo de sus propias elecciones. También en este caso, lo "más vida" se traduce como "debes cambiar de vida para mejorarte", lo cual se puede realizar solo si uno es capaz de auto-reglamentarse y de dirigir cualquier comportamiento personal hacia una optimización del propio capital humano en función de un aumento de las capacidades productivas. ${ }^{9}$

Por lo que se evidencia, para Sloterdijk, este tipo de fitness solo representa una vulgarización de los ejercicios de matriz ascética porque, a pesar de producir una auto-plasticidad, no presenta ninguna tensión vertical: solo de esta puede brotar una nietzscheana transevaluación de los valores. Queda por entender quién tiene los instrumentos para auto-comprender la falta de autenticidad de su propia vida, necesaria premisa para adoptar el imperativo metanoico relacionado con el hecho de 'debes cambiar de vida', y entregarse a una vida ascética. Sin embargo, se puede dar el riesgo

7. Cfr., P. Dardot, C. Laval, La nouvelle raison du monde. Essais sur la société néolibérale, La découverte, París, 2009.

8. L. Bazzicalupo, Dispositivi e soggettivazioni, Mimesis, Milano, 2013, pp. 30-32.

9. La categoría de 'capital humano' tuvo una difusión especial sobre todo a partir de la década de los años sesenta, cuando Theodore Schultz, exponente de la Escuela de Chicago, durante la Conferencia titulada "Investment in Human Capital" bosqueja la relación entre instrucción, productividad y crecimiento económico. Sobre este tema, véase G. S. Becker, Human Capital. A theoretical and Empirical Analysis with special Reference to Education, The University of Chicago Press, Chicago-London, 1964. 
de autorizar una ética y una política de tipo elitista, en donde la masa está sometida a los engañosos imperativos de la falsa fitness, mientras que solo algunos son capaces de plantear la pretensión superior que los lleva 'a conquistar la montaña improbable.'10 Sin embargo, al final de aquella escalada, el riesgo —o quizá la esperanza- es el de no encontrar nada más que un monasterio personal, fuera del mundo. En resumidas cuentas, la potenciación de la vida como imperativo ético corre el peligro de ser fácilmente instrumentalizada por la retórica neoliberista del empowerment $\mathrm{y}$, al mismo tiempo, de corroborar una lógica profundamente individualista y elitista. Por otra parte, si — tal como sostiene Sloterdijk — la crisis global puede ofrecer una extraordinaria oportunidad de $\mathrm{cambio}^{11}$, no se puede dejar de lado el hecho de que ella puede, en cambio, ser interpretada como un dispositivo capaz de integrar la clásica función de control social puesta en marcha por la governance neoliberal con un mecanismo de interiorización de una culpa que hipoteca el futuro por medio de una extensión ilimitada de la deuda presente: de tal manera que nuestro entrenamiento sea un sacrificio que no implica ninguna ascensión. ${ }^{12}$ Aunque aceptáramos la tesis según la cual la crisis de 1929 fue la que favoreció la afirmación de políticas de tipo keynesiano, sin embargo no es posible olvidarse de que fueron ocasionadas también y sobre todo por los numerosos paros y huelgas que se subsiguieron en aquellos años. Pues bien, aunque se quieran buscar a toda costa unas analogías - y esto no es totalmente posible por el muy diferente contexto histórico-político-económico- ${ }^{13}{ }^{3}$, es menester recordar que la lucha de muchos permitió un breve, aunque extraordinario, proceso de emancipación, y no las 'ascensiones' de pocos.

Claro está, el 'paso ético' no es algo nuevo, igual que los problemas que de él proceden - tanto en las variantes normativizantes-trascendentales según Habermas, como en aquellas pragmático-inmanentistas según Foucault — no son irrelevantes, sobre todo por lo que al perfil político se refiere. La construcción de una 'otra vida', entendida como

10. En este caso, se nos refiere al título de la obra de Richard Dawkins usado por P. Sloterdijk, Du musst dein Leben ändern. Über Anthropotechnick, Shurkamp Verlag, Frankfurt am Main, 2009, pp. 185-9.

11. Ibidem, pp. 699-714. La convicción según la cual la crisis puede abrirse paso, hasta proporcionar una ruptura en el orden neoliberal es bastante difundida, aunque según perspectivas muy diferentes de aquella de Sloterdjk. Me limito a citar, desde una posición post-marxista y revolucionaria, a S. Žižek, Living in the End Times, Verso, London, 2010. Por lo que a una acepción de la crisis como posibilidad de reducción del turbo-capitalismo se refiere, véase S. Latouche, Vers une société d’abondance frugale. Contresens et controverses sur la décroissance, 1001 Nuits-Fayard, París, 2011. Confróntese también M. Serres, Temps des crise, Éditions Le Pommier, París, 2009.

12. Cfr., M. Lazzarato, La fabbrica dell'uomo indebitato. Saggio sulla condizione neoliberista, Derive Approdi, Roma, 2012. Respecto de la relación entre ascetismo como práctica sacrifical y economía como forma de poder, cfr. E. Stimilli, Il debito vivente. Ascesi e capitalismo, Quodlibet, Macerata, 2011.

13. Sobre este aspecto véase mi obra: S. Luce, Keynes e i nipotini in crisi: la svolta bioeconomica, en L. Bazzicalupo y A. Tucci (ed.), Il grande crollo. È possibile un governo della crisi economica?, Mimesis, Milano, 2010, pp. 49-64. 
una vida que corresponde a un dominio del yo, a una ascésis que reconstituye la propia soberanía respecto de la veridicidad de los discursos, puede producir actos libres y creativos que acabarán afectando la condición del individuo, mientras ella tiene, o puede tener, un valor político solo si es también un acto social, una práctica que encuentra otras experiencias/subjetivizaciones en el interior de un conjunto de relaciones que experimentan estilos de vida capaces de interrogar y problematizar el presente. Solo así la estilización de la existencia puede ser una acción política, además de ética, capaz de expresar activamente el radicalismo del disenso hacia aquellas verdades dominantes que enjaulan y someten nuestra condición de vivientes.

Traducción del italiano de M. Colucciello 